Article

\title{
Estimation of the Buildings Seismic Vulnerability: A Methodological Proposal for Planning Ante-Earthquake Scenarios in Urban Areas
}

\author{
José Luis Ródenas, Salvador García-Ayllón (iD) and Antonio Tomás * \\ Department of Civil Engineering, Universidad Politécnica de Cartagena, 30203 Cartagena, Spain; \\ jlrq0@alu.upct.es (J.L.R.); salvador.ayllon@upct.es (S.G.A.) \\ * Correspondence: antonio.tomas@upct.es; Tel.: +34-968-325-653
}

Received: 19 June 2018; Accepted: 19 July 2018; Published: 23 July 2018

Featured Application: Geographic Information System (GIS) estimation of ante-earthquake scenarios through a more functional and standardized method of seismic vulnerability evaluation of reinforced concrete buildings in urban areas.

\begin{abstract}
In spite of the enhancements related to building construction, many regions still present a major level of seismic risk as a consequence of the high vulnerability of the urban configuration of their cities. An improved method to assess the seismic vulnerability of buildings in urban areas is proposed in this contribution in order to advance the management of seismic emergency scenarios. The methodology, mainly based on the cadastral database, allows for a more standardized implementation as a function on the typological, structural, and urban parameters of the buildings, reducing the level of uncertainties linked to these methodologies and giving continuity to the different RISK-UE published works. The generalization of the method to any urban area has also been improved by means of removing the parameters whose calibration is associated with a specific area. The methodology has been put into practice in the urban area of the city of Lorca (SE Spain), in the aftermath of the earthquake of 11 May 2011, due to the availability of well-documented data reported from this seismic event. The proposal, when it is combined with Geographic Information System (GIS) techniques, provides valuable information for the planning and management of post-earthquake emergency situations.
\end{abstract}

Keywords: seismic vulnerability assessment; emergency planning; post-earthquake management

\section{Introduction}

The study of the seismic global performance of buildings continues to constitute one of the main purposes of Seismic Engineering. Some of the last seismic disasters (Nepal 2015, Ecuador 2016, Italy 2016, and Mexico 2017) have once again revealed the inadequate performance of many existing buildings against the seismic action. In this sense, seismic design codes have usually been improved after each earthquake disaster, but old constructions have remained unprotected by new techniques. Nevertheless, poor behavior has also been observed in those buildings designed with recent seismic regulations [1-3].

At an urban scale, the seismic risk of a structure can be defined as the potential expected damage that may happen to it in a specified time frame of exposure [4]. This property is related to the seismic hazard (the probability of occurrence of a seismic event of certain severity in a specific site and during a determined period of exposure) and to the intrinsic predisposition of the building to be affected upon receiving the impact from a quake of a certain severity, expressed as seismic vulnerability. 
This parameter depends on the design and construction characteristics of the building (structural configuration, geometric form, ductility of the materials, etc.), therefore constituting an independent factor from the seismic action.

In some territories, such as the Euro-Mediterranean, the proportionally low frequency of seismic phenomena in comparison to other regions has often generated a decline in the social and institutional awareness of the seismic danger. This context has on many occasions driven to scant rigor in the application of the existing regulations and a somewhat lax attitude in the application of good practices of seismic design $[5,6]$. Without doubt this situation raises the levels of seismic vulnerability in many urban areas and the expected losses in the event of an earthquake. In this sense, the seismic vulnerability evaluation of existing buildings can be carried out using Mechanical or Macroseismic methods [4].

Consistent with the recent philosophy of seismic design known as Performance Based Design, mechanical or analytical methods consider the seismic demand and the capacity of the building constructions according to its respective spectrums developed from a nonlinear dynamic study. Proposed initially in previous studies $[7,8]$, these methodologies allow for a comprehension of the structural behavior of buildings for each level of impact when they are exposed to a seismic action, even including the contribution of masonry infills in the seismic response of a building construction [9-11].

Moreover, macroseismic —or empirical—methods allow for the performance of a specific building to be characterized based on a statistical analysis of observed damage during past earthquakes. From a series of characteristics related to the typology and the structural design of each building, these models estimate the seismic susceptibility according to vulnerability classes, through descriptors or qualitative variables [12,13], or according to vulnerability indexes by means of a numerical valuation as a result of the quantification of the above-mentioned parameters. These methods include the Italian Method [14], the Japan Method [15], NZSEE and US Guidelines [16,17], the Vulnerability Index Method [18], or recent European Commission reports [19].

For seismic risk assessment in urban areas, the RISK-UE Project [20] stated two methodologies. The first one, named the Level 1 method (LM1) and obtained from empirical procedures, typifies the seismic danger of an urban area according to the European Macroseismic Scale (EMS-98), and the vulnerability of the buildings through a vulnerability index developed in line with the Vulnerability Index Method. The second one, named as Level 2 method (LM2), models seismic action using the corresponding spectrum of demand and the seismic vulnerability consistent with the capacity spectrum of the structure [21].

In this sense, the Vulnerability Index Method (VIM) constitutes a process that combines the vulnerability classes of the EMS-98 scale and the Italian method [14] for the characterization of the seismic vulnerability of buildings [22,23]. These methodologies are based on vulnerability indexes that have their roots in a sequence of basic vulnerability indexes obtained according to the structure typology of the building; they are modified with a series of factors related to the structural and constructive characteristics of each building, in a standardized way. Concerning the VIM method, the basic vulnerability indexes $I v$ were developed through the inventory of damage in buildings found in the European countries involved in the project. Thus, the seismic performance of the most habitual structural configurations in urban areas can be characterized by means of the Building Typology Matrix (BTM) [18].

The vulnerability indexes for some building typologies of BTM, consequently included in a previous study [24] as participants of the RISK-UE Workgroup, are shown in Table 1. This proposal standardizes the RISK-UE curves by empirical damage models, consistent with the fuzzy set theory. Similar to the qualitative definitions interpreted through membership functions $\chi$ proposed by previous studies $[23,25]$ for the vulnerability categories of the EMS-98 scale, RISK-UE considers a series of membership functions for each structural configuration. A function $\chi$ defines the belonging of single values of a certain parameter to a specific set: the value of $\chi$ is 1 when the degree of belonging is reasonable; between 0 and 1 shows that the value of the parameter is infrequent but possible; and $\chi$ 
is 0 when the parameter is not associated to the set. Thus, VIM sets a value $I v^{*}$ as the most possible vulnerability index $(\chi=1)$, a couple $\left[I v^{-}, I v^{+}\right]$that generates a commendable interval $(\chi=0.6)$, and an interval $\left[I v^{\mathrm{min}}, I v^{\mathrm{max}}\right]$ with the minimum and maximum limits $(\chi=0.2)$, characterized as least probable or exceptional.

Table 1. Basic vulnerability indexes of reinforced concrete building typologies defined in Building Typology Matrix [18,24].

\begin{tabular}{cccccccc}
\hline \multicolumn{2}{c}{ Typologies } & Building Type & $\mathbf{I} \boldsymbol{v}^{\text {min }}$ & $\mathbf{I} \boldsymbol{v}^{-}$ & $\mathbf{I} \boldsymbol{v}^{*}$ & $\mathbf{I} \boldsymbol{v}^{+}$ & $\mathbf{I} \boldsymbol{v}^{\text {max }}$ \\
\hline \multirow{2}{*}{ Reinforced } & RC1 & Concrete moment frame & 0.140 & 0.330 & 0.484 & 0.640 & 0.860 \\
Concrete & RC2 & Concrete shear walls & 0.140 & 0.210 & 0.384 & 0.510 & 0.700 \\
& RC3 & Dual system & 0.060 & 0.127 & 0.522 & 0.880 & 1.020 \\
\hline
\end{tabular}

The VIM method adapts this basic index of vulnerability $I v_{t}$ in line with a series of values of penalty or improvement called modifiers of behavior, according to some structural and urban planning constraints such as the level of design code, the number of floors of the buildings, the geometric and stiffness regularity, or the relative position of the building in the neighborhood.

Taking into account different experiences after post-earthquake evaluations [16,26,27], these standards are defined in a \pm 0.02 range for an interval between -0.08 and +0.08 in order to incorporate them into the characterization of the seismic vulnerability. Since the previous described version [18] a series of reviews have been performed in the definition and numerical evaluation of these behavior modifiers [23,25,28,29], calibrating the influence of several dispositions (i.e., sloping ground difference of height between close buildings, irregularity in plant or elevation, etc.), in the seismic analysis of buildings.

Furthermore, the methodology considers an additional factor-the regional modifier-, linked to the specific constructive idiosyncrasy of the study area, the existing seismic design codes, time of construction, or of the judgment of experts from empirical information proceeding from actual observed damage. In order to estimate this modifier, no widely accepted proposal is currently available, with different values in the range of $[-0.088,0.08]$ for masonry typologies and $[-0.022,0.14]$ for reinforced concrete buildings $[23,25,29]$.

Finally, the correlation between expected seismic damage and the seismic vulnerability assessed is expressed in the LM1 method through a semiempirical vulnerability function linked to two parameters: the vulnerability index $I v_{b}$, and the macroseismic intensity $I$ in the EMS-98 scale [30]:

$$
\mu_{\mathrm{D}}=2.5\left[1+\tanh \left(\frac{I+6.25 I_{v b}-13.1}{Q}\right)\right]
$$

where $Q$ is a ductility factor of value 2.3 for many of the building configurations of BTM [19], and $\mu_{D}$ is the mean damage degree developed in the EMS-98 scale (Table 2). After the calculation of this index, RISK-UE is used in order to define the distribution of damage probability through a beta type function, more adaptable than the binomial one of the EMS-98 scale [30].

Table 2. Mean damage grade defined in the RISK-UE LM1 method [12].

\begin{tabular}{cl}
\hline Damage Grade & \multicolumn{1}{c}{ Description } \\
\hline 0: Null & No damage \\
1: Slight & Negligible to slight damage. No structural damage, slight nonstructural damage \\
2: Moderate & Moderate damage. Slight structural damage, moderate nonstructural damage \\
3: Substantial to heavy & Substantial to heavy damage. Moderate structural damage, heavy nonstructural damage \\
4: Very heavy & Very heavy damage. Heavy structural damage, very heavy nonstructural damage \\
5: Destruction & Destruction. Very heavy structural damage. Total or partial collapse \\
\hline
\end{tabular}


In this sense, the existence of well-documented damaging earthquakes (such as that in Lorca in 2011) offers an interesting occasion to enhance the empirical methodologies to assess the seismic answer of buildings. This paper is focused on the analysis of the planning and management of ante-earthquake scenarios of emergency contexts by developing methods for the seismic vulnerability assessment of buildings in urban areas. After an introduction section where the seismic vulnerability of buildings has been summarized, a developed model mainly based on the cadastral database is proposed, documenting the method through a field study of the buildings damaged in the Lorca earthquake, 2011 (see Supplementary Materials). In the Results section, the application of the proposal for the planning and management of seismic scenarios is exposed, with the conclusions obtained being provided in the last section.

In this sense, this contribution is aimed at the analysis of the seismic performance of reinforced concrete buildings, since this typology is usually the most common in modern urban areas. Nevertheless, the importance of seismic behavior assessment of masonry structures in historic centers must be highlighted for a necessary conservation of the urban heritage. The first studies for assessing the seismic vulnerability of buildings already included the analysis of this typology of structures [14,18]. Recent studies have improved these methodologies in order to give a better estimation of the mechanical performance of this typology of building [31,32].

\section{Materials and Methods}

\subsection{An Adjusted Technique for Evaluating the Susceptibility of Buildings to Potential Damage}

The global vulnerability index $I v_{b}$ of a building can then be assessed using the following expression [24]:

$$
I_{v b}=I_{v}+\Delta M_{R}+\sum_{j=1}^{n} M_{C j}
$$

where $I v$ is the basic vulnerability index of the structural configuration shown in Table $1 ; \Delta M_{R}$ is the regional modifier; and $\Sigma M_{C}$ are the individual set of modifiers of behavior taking into account the structural and urban planning parameters for each building assessed.

Equation (2) reflects the importance of the quantification of each behavior modifier in order to accurately evaluate the seismic vulnerability of buildings in urban areas. The reviews proposed for these parameters in the LM1 method framework $[23,25,28,29]$ have concentrated mainly on the analysis of those parameters related to the impact of different urban planning dispositions in the seismic answer of the buildings (short column, soft storey, etc.). However, other constraints related to the scientific rigor of the seismic design code that has been used or the effect of the natural period in the building seismic answer need to be adjusted to the real behavior of reinforced concrete buildings, in order to distinguish it from the behavior of unreinforced masonry structures.

Thus, the improved technique for the evaluation of the seismic vulnerability through the LM1 method proposed in this contribution revises the definition of the modifiers of behavior of the methodology. Providing continuity with the currently available reviews of the method, the new values are proposed from an analysis of these previous works and an evaluation of the seismic performance of buildings in recent earthquakes, according to the level of the seismic codes and the construction characteristics usually present in reinforced concrete buildings. The modifiers projected to get the vulnerability index Iv-b of a building can be observed in Table 3. 
Table 3. Behavior modifiers proposed for the LM1 VIM method, conditioned to the level of the seismic code design assigned. The modified values are indicated in bold. Further description of each element can be found in [25].

\begin{tabular}{|c|c|c|c|c|c|}
\hline \multicolumn{2}{|c|}{ Modifier of Behavior } & \multicolumn{4}{|c|}{ Level of Design Code } \\
\hline \multicolumn{2}{|c|}{ Level of seismic and structural design code } & $\begin{array}{l}\text { Pre-code } \\
0.16\end{array}$ & $\begin{array}{l}\text { Low code } \\
0.08\end{array}$ & $\begin{array}{l}\text { Medium code } \\
0\end{array}$ & $\begin{array}{l}\text { High code } \\
0\end{array}$ \\
\hline $\begin{array}{l}\mathrm{N}^{\mathrm{o}} \text { storeys above } \\
\text { ground }\end{array}$ & $\begin{array}{c}0 \text { to } 3 \\
4 \text { to } 7 \\
\geq 8\end{array}$ & $\begin{array}{c}0.04 \\
0 \\
-0.04\end{array}$ & $\begin{array}{c}0.04 \\
0 \\
-0.04\end{array}$ & $\begin{array}{c}0.04 \\
0 \\
-0.04\end{array}$ & $\begin{array}{c}0.04 \\
0 \\
-0.04\end{array}$ \\
\hline \multicolumn{2}{|l|}{ Plant irregularity } & \multicolumn{4}{|c|}{$\begin{array}{c}0.04(\mathrm{RC}<0.5) \\
0.02(0.5>\mathrm{RC}>0.7)\end{array}$} \\
\hline \multicolumn{2}{|c|}{ Irregularity in elevation } & \multicolumn{4}{|c|}{$\begin{array}{r}0.04(d<0.04) \\
0.02(1>d>3)\end{array}$} \\
\hline \multicolumn{2}{|c|}{ Short column } & 0.08 & 0.08 & 0.08 & 0.08 \\
\hline \multicolumn{2}{|c|}{ Insufficient seismic structural joint } & 0.04 & 0.04 & 0.04 & 0 \\
\hline \multicolumn{2}{|c|}{ Slope of the ground } & 0.04 & 0.04 & 0.04 & 0.04 \\
\hline $\begin{array}{l}\text { Relative position in the } \\
\text { block of buildings }\end{array}$ & $\begin{array}{c}\text { Intermediate } \\
\text { Corner } \\
\text { Full corner } / \text { Header }\end{array}$ & $\begin{array}{c}-0.04 \\
0.04 \\
0.06\end{array}$ & $\begin{array}{c}-0.04 \\
0.04 \\
0.06\end{array}$ & $\begin{array}{c}-0.04 \\
0.04 \\
0.06\end{array}$ & $\begin{array}{c}-0.04 \\
0.04 \\
0.06\end{array}$ \\
\hline \multicolumn{2}{|c|}{ Relation with adjoining buildings } & \multicolumn{4}{|c|}{$\begin{array}{c}{[-0.04,0.04]} \\
\mathrm{f} \text { (relative height between buildings) }\end{array}$} \\
\hline Soft s & rey & 0.2 & 0.2 & 0.2 & 0.2 \\
\hline
\end{tabular}

First, a new modifier that considers the scientific rigor of seismic and structural design code is defined. It can adopt the values $0.16,0.08$, or 0.00 , according to the behavior typically detected in the structures designed with outdated and inaccurate seismic codes [33-35]:

- 0.16: Case of pre-code buildings (calculated with no seismic regulations). In this situation, the following conditions are concurrently met: (i) use of simplified methods for the analysis of the building; (ii) the nonexistence of seismic construction requirements or good practices for the design of the structure; (iii) the lack of seismic construction requirements or good practices for the design of the foundation; and (iv) the probable poor state of conservation and/or quality of materials.

- 0.08: Case of low code buildings (performed with early versions of seismic codes). The implementation of some seismic recommendations for the structure and foundation in the codes makes this modifier decrease from 0.16 to 0.08 , taking into account that only the simplified analysis methods and the probable poor state of conservation and/or quality of materials are considered in this case.

- 0.00 : Case of medium or high code buildings (performed with latter seismic codes). A value of 0.00 is given to this modifier taking into consideration that more truthful analysis systems have been implemented and a superior state of conservation and quality of materials is expected.

Thus, after a classification of the different national seismic codes this parameter can be obtained depending on the construction period of the building, which can be estimated from the cadastral database.

Moreover, the parameter linked to the number of storeys above ground is modified fitting its performance depending on the form of the response spectrum defined in Eurocode- 8 and the corresponding natural period of the buildings. Damage in small constructions with cracks in masonry infill walls at the ground floor and failures at the end of columns is generally identified in this type of buildings due to their higher stiffness $[5,35,36]$. Thus, the behavior lower height building is penalized 
with a value of 0.04 , whose natural frequency coincides with the amplified area of constant spectral acceleration, and the vulnerability of the highest buildings is diminished $(-0.04)$ coinciding with the spectrum area of decreasing accelerations. Nevertheless, as high-rise buildings are seismically vulnerable to P-Delta and higher mode effects, it would be advisable for the value of the behavior modifiers to be adjusted based on the availability of more well-documented earthquakes.

Furthermore, since in reality the majority of the buildings in urban areas, especially those located on low-to-moderate seismicity territories, have no seismic structural joint between buildings (or such a joint is not wide enough or has not been executed correctly), cracks in masonry infill walls and even in structural elements can frequently be detected in the joint between contiguous constructions [27,34]. Consequently, a penalty value of 0.04 has been conservatively reflected, excluding those buildings executed with high level seismic regulations.

The two modifiers linked to the configuration of the foundation and the conservation state of the building, included in the former versions of the VIM method, have been removed since they are problematic to evaluate in most cases and since these parameters are already considered in the first modifier mentioned, relating to the level of the seismic design code. Thus, part of the uncertainty associated to the vulnerability assessment can be reduced. Likewise, taking into account the definition of the modifier $\Delta M_{R}$ presented in this paper, its removal in the assessment of the vulnerability index $I v_{b}$ has been proposed, since the aspects involved in its evaluation, such as the specific constructive dispositions or the date of construction, are in practice included in the behavior modifier related to the level of the seismic design code. The generalization of the method to any urban area has been consequently simplified since a parameter requiring calibration depending on the area of study has been deleted, summarizing its value in just one parameter depending on the seismic design code.

Therefore, the proposed model enables to improve a more functional and operable approach of the technique using cadastral survey data and performing an on-site inspection of the assessed area, depending on the typological, structural, and urban configurations of the buildings.

\subsection{Application of the RISK-UE LM1 Method for Seismic Vulnerability Assessment to Emergency Management: Lorca (Spain) Earthquake, 2011 Case Study}

In order to apply the improved method proposed in this contribution, the Department of Civil Engineering of the Technical University of Cartagena carried out a field study to register all the seismic behavior in reinforced concrete buildings affected by the Lorca earthquake that occurred in 2011. Despite having a moderate magnitude of $5.1 \mathrm{Mw}$, the quake on 11 May 2011 caused important casualties ( 9 people died and more than 300 were injured) and important structural damage which forced more than 10,000 people to be evacuated from their homes during the first days [36]. Considering the comparatively small size of the city of Lorca and the homogenous results that the seismic event produced in the urban area, the quake was defined with an EMS-98 macroseismic intensity $\left(I_{E M S-98}\right)$ of VII [37] in the main neighborhoods of the city.

During the campaign performed in the urban area of Lorca, damage linked to the quake and several urban features that may guide its seismic answer were registered for each building studied in the research, along with the actual damage grade observed. An example of the document used to collect data is included in Figure 1, inspired from different works on the rapid evaluation of seismic damages in buildings [38,39], but which is not contained in these works. 


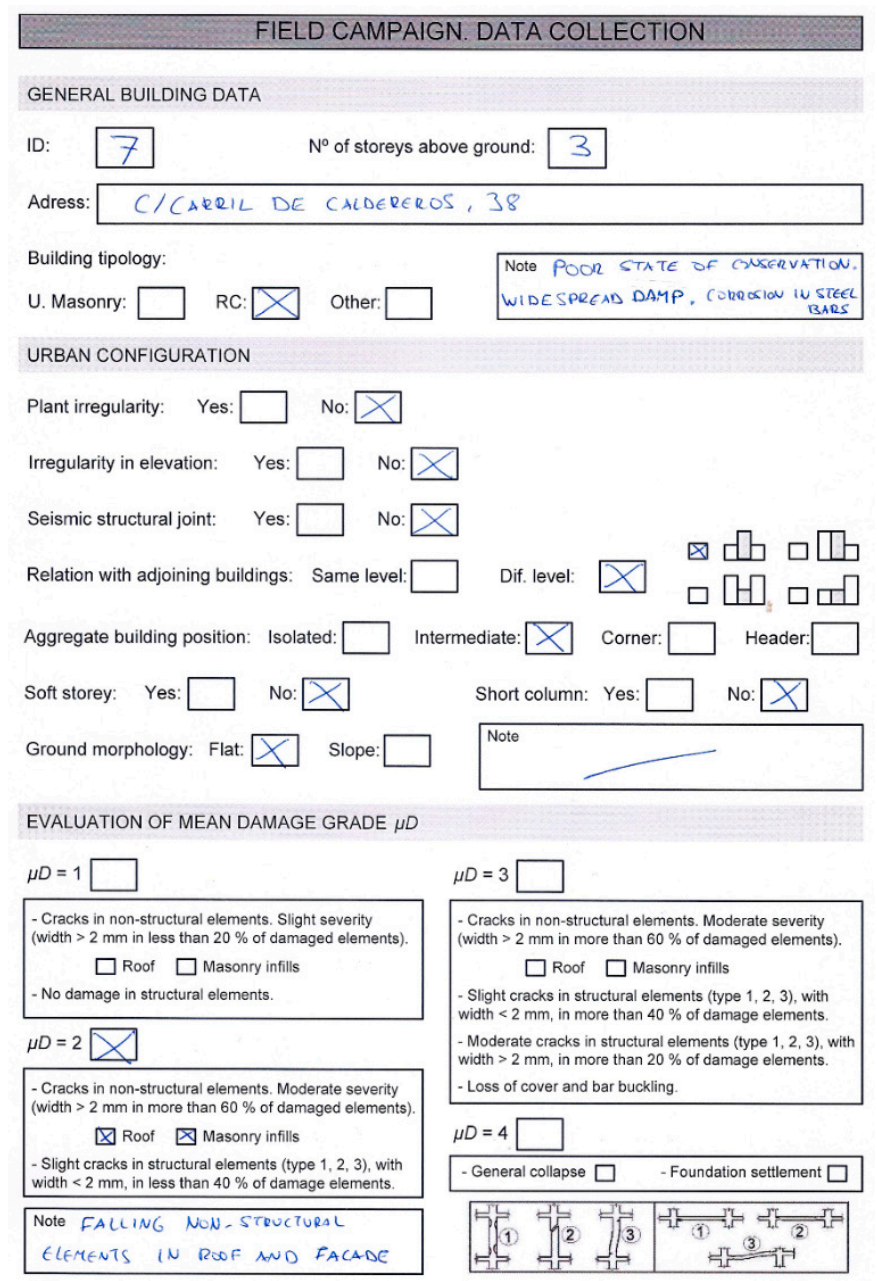

Figure 1. Example of a template used in the field campaign to collect data.

The template consisted of three sections covering: (i) general data, such as the building description or the address; (ii) the constructive topics and urbanistic conformation of the building, such as the presence of short columns or soft storeys; and (iii) the evaluation of EMS-98 damage degree $\mu_{\mathrm{D}}$. In the second phase of the work, the collected data was completed with the cadastral information required to implement the remaining modifiers of behavior in the RISK-UE LM1 methodology, such as the year of construction, comparing also the modifiers obtained in the field campaign, such as the number of storeys above ground or the aggregate building position. Nevertheless, for applying the proposal on a large scale in further studies it is highly recommended to use the cadastral database to allow for a more standardized implementation of the methodology.

Based on this input data collection, the vulnerability indexes and the expected damage grade according the LM1 method in each building were estimated. After a comparison and validation process, from an early sample of 1050 buildings, 406 homogeneous cases were finally selected, eliminating outliers or those where adequate information was not available. The construction period distribution of the analyzed buildings, according to the Spanish seismic codes, is graphically represented in Figure 2. A uniform distribution in the urban area of Lorca can be observed. 


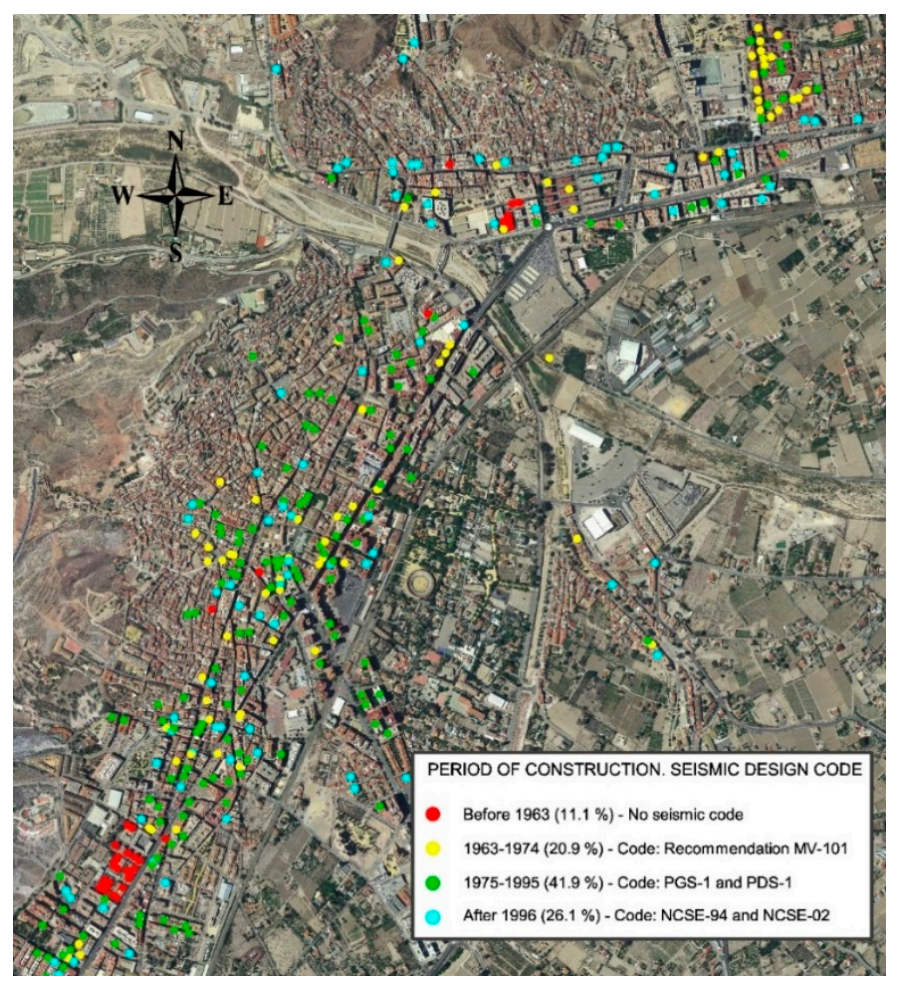

Figure 2. Graphical construction period distribution of the buildings evaluated in Lorca, according to the different Spanish seismic codes that exist.

The distribution of the actual EMS-98 damage grade detected in buildings is shown in Figure 3. As an example, within the group of structures built before 1963, 46.7\% presented high damage levels $\left(\mu_{D}=3\right)$ whereas this percentage diminished to $8.5 \%$ in the buildings built after 1996. In contrast, only $8.9 \%$ of the buildings belonging to the first group presented a slight grade of damage $\left(\mu_{D}=1\right)$, with this value reaching $43.4 \%$ in the more recently built buildings.

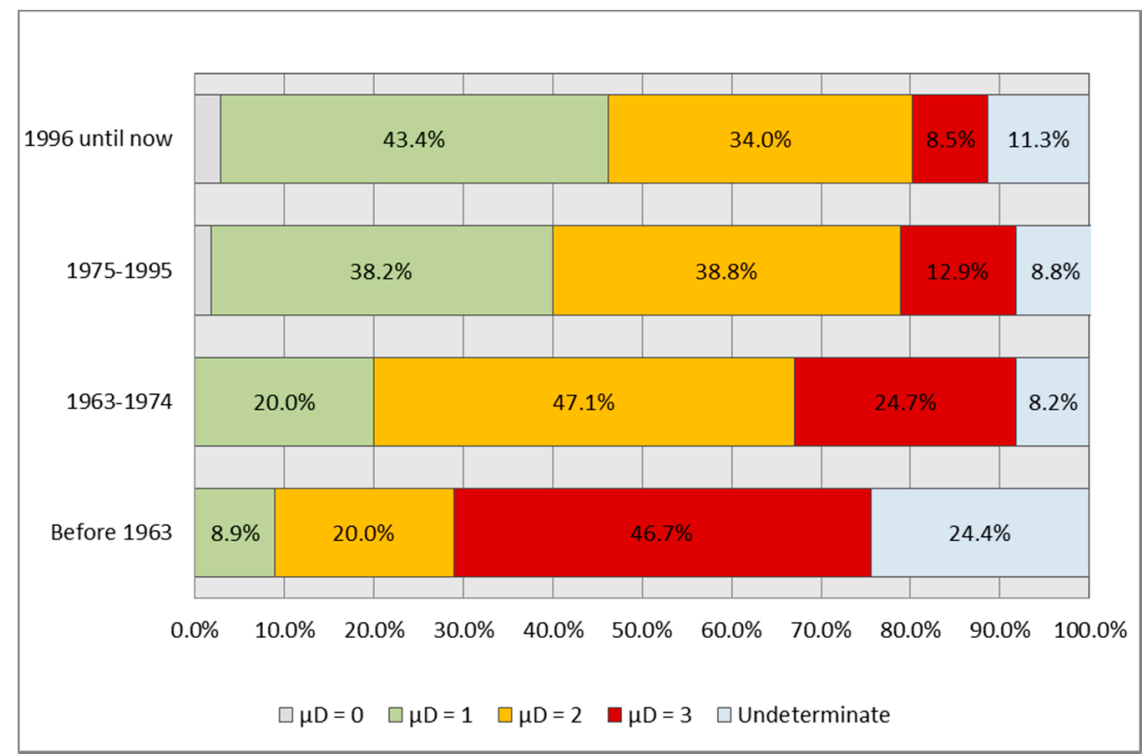

Figure 3. Distribution of the mean actual EMS-98 damage grade observed on RC buildings after the Lorca earthquake, 2011, according to the period of construction. 
Thus, the damage grade estimated according to the proposed model of the LM1 method for an earthquake of $I_{E M S-98}=$ VII has been compared with the corresponding damage observed in the 2011 Lorca earthquake. Figure 4 shows the distribution of both values obtained from the input collection data. For each building, the estimated mean damage grade $\mu_{D}{ }^{*}$ is plotted with its corresponding vulnerability index $I v_{b}$ along with the possible range $\left[\mu_{\mathrm{D}}{ }^{-}, \mu_{\mathrm{D}}{ }^{+}\right]$associated with the interval $\left[I v^{-}, I v^{+}\right]$ defined in BTM. Moreover, the observed EMS-98 damage $\mu_{D}$, plotted as a cross mark, is shown with the same $I v_{b}$ values. As can be observed, for an earthquake of $I_{E M S-98}=$ VII the damage simulated by the proposed LM1 method remains below the levels of actual observed damage.

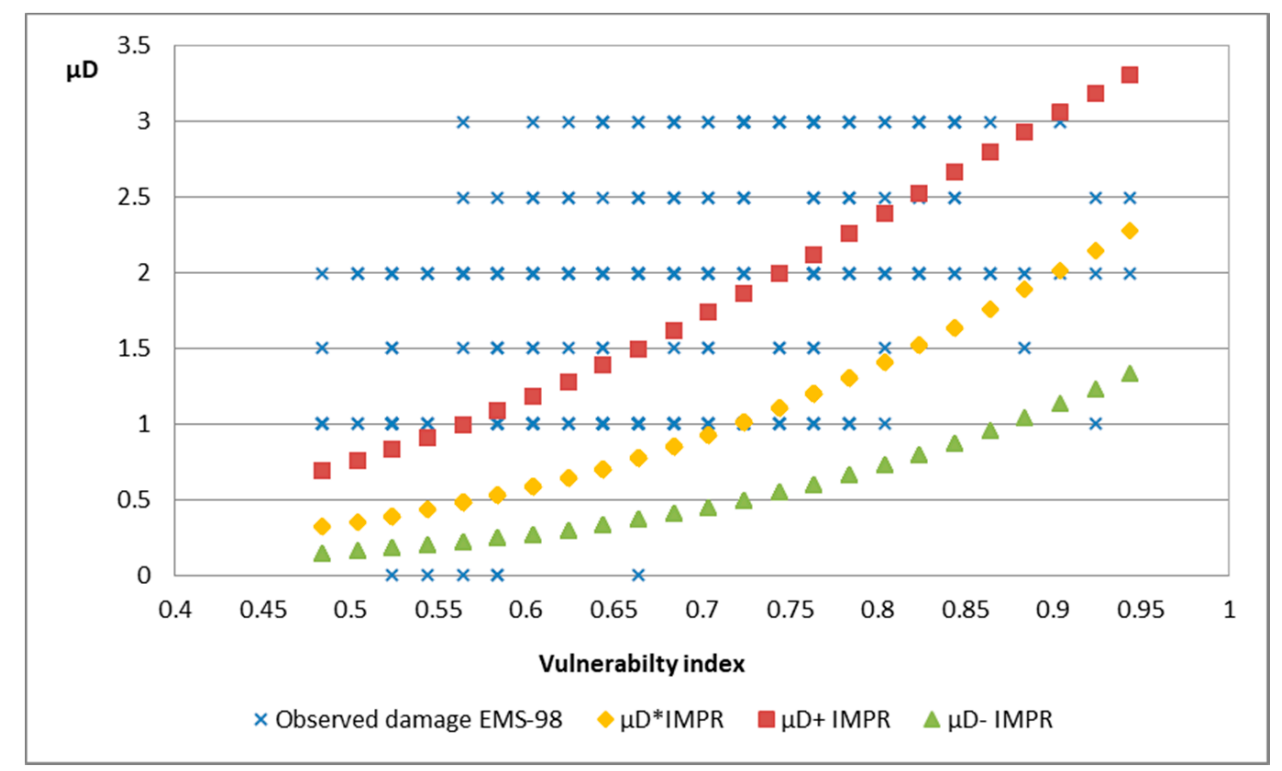

Figure 4. Graphical comparison between EMS-98 observed damage on RC buildings from earthquake of Lorca (blue crosses), and the mean damage degree calculated with the RISK-UE LM1 model for an $I_{E M S-98}=$ VII earthquake, where $\mu_{\mathrm{D}}{ }^{*}$ is the representative mean damage value (yellow) and $\left[\mu_{\mathrm{D}}{ }^{-}, \mu_{\mathrm{D}}{ }^{+}\right]$ the range of the estimated mean damage degree (red and green dots) [33].

The statistical measures of the vulnerability indexes and the mean damage grade $\mu_{\mathrm{D}}$ defined in the EMS-98 scale of the RC analyzed buildings are shown in Table 4. As can be observed, the mean value obtained of the vulnerability index is 0.677 with a standard deviation of 0.101 , whereas the mean value of damage grade estimated is 0.753 with a standard deviation of 0.288 . The building configuration $\mathrm{RC} 1$ has been designated to obtain the vulnerability index [18]. A new variable $D_{i}=A D_{i}-\mu_{\mathrm{Di}}$ has been evaluated, where $A D_{i}$ is the actual EMS-98 damage observed for every building $i$, and $\mu_{\mathrm{Di}}$ is the corresponding mean damage grade obtained according to the proposed model of the LM1 method.

Table 4. Measures of central tendency of the vulnerability index $I v_{b}{ }^{*}$, the mean damage grade $\mu_{D}$ and the new variable $D$ of the reinforced concrete studied buildings according to the proposed model of the LM1 method.

\begin{tabular}{cccc}
\hline Damage Grade & $\boldsymbol{I} \boldsymbol{v}_{\boldsymbol{b}}{ }^{*}$ & $\boldsymbol{\mu}_{\mathrm{D}}$ & $\boldsymbol{D}$ \\
\hline Sample mean & 0.677 & 0.753 & 0.91 \\
Sample standard dev. & 0.101 & 0.288 & 0.694 \\
Minimum & 0.404 & 0.26 & -1.14 \\
Maximum & 0.944 & 2.84 & 2.31 \\
\hline
\end{tabular}




\section{Results}

The possibility of evaluating the seismic performance of the stock of buildings of an urban area from an analysis of the cadastral database contributes information for the management of the effects of the different damage scenarios in a rapid and standardized way. In this respect, the role of Geographical Information System (GIS) in urban natural risks analysis constitutes an effective tool for the integral management of this type of situations.

In this sense, the graphical picturing of vulnerability indexes and expected damage in buildings, through a geo-referencing process, makes it possible to recognize the most vulnerable areas of the city and planning different ante-earthquake emergency scenarios (see Figure 5).

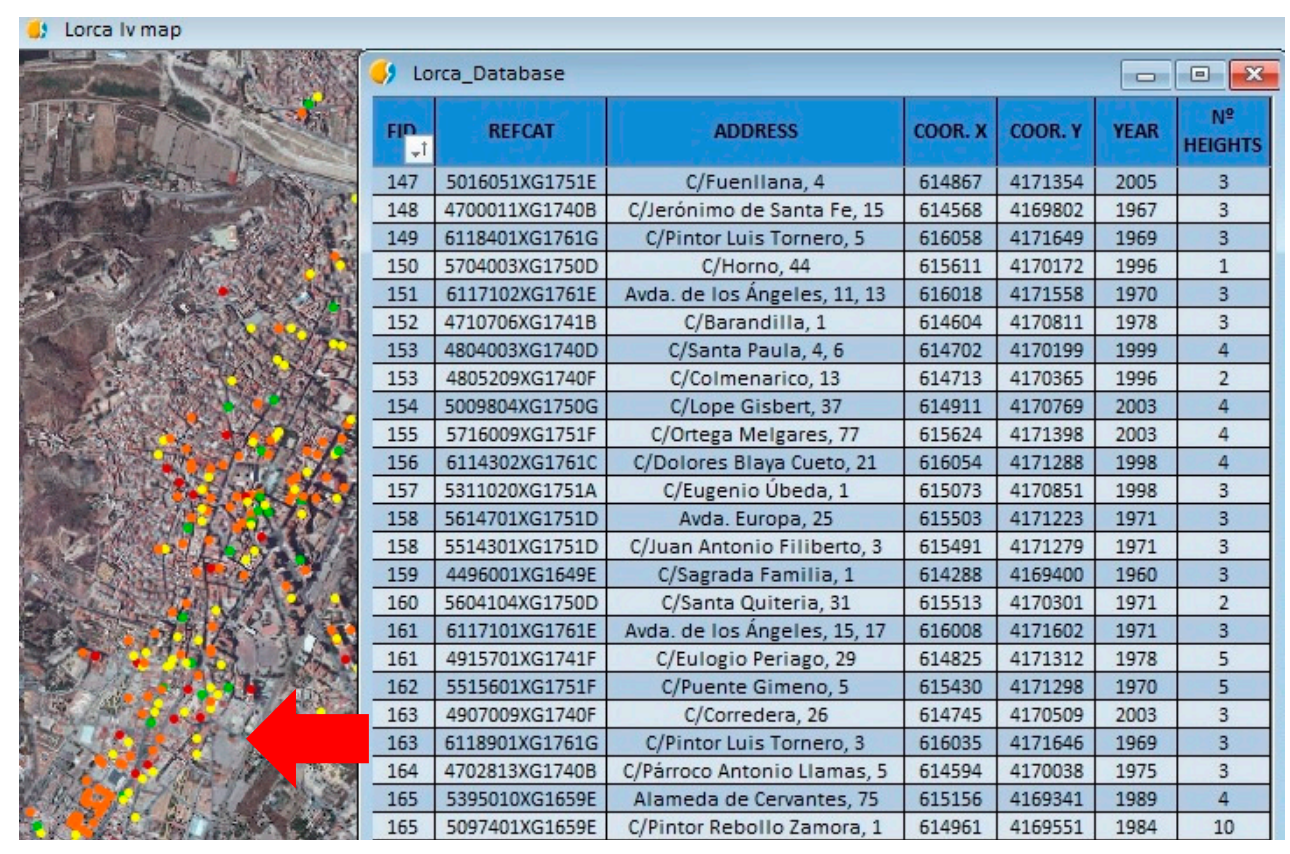

Figure 5. Implementation of cadastral database of reported damage buildings used in this case study.

Thus, the geospatial dissemination of the vulnerability indexes of RC buildings studied in Lorca, obtained according to the improved LM1 method proposed in this work, is described in Figure 6a by means of a density heat map estimation. Similarly, the distribution of expected damage grade obtained according the proposed model for an $I_{E M S-98}=$ VII earthquake can be observed in Figure $6 \mathrm{~b}$.

In both cases, in spite of the damage distribution not being homogeneous, the modeled results reflect that the most vulnerable areas to a certain seismic action were mainly concentrated in the northeast neighborhoods and the central and southwestern areas of the city, as has been presented in some studies [27,40]. Precisely, these zones suffered widespread damages in buildings after the 11 May 2011 earthquake, even with the collapse of one entirely residential building [5,6].

Considering a detailed scale, an example of how this method allows for an analysis of damage scenarios in an individualized way for each building and each neighborhood of the urban area is shown in Figure 7. As can be observed, the above-mentioned evaluation not only depends on the structural characteristics of the building but also on urban parameters such as the relative position within the block of buildings, the relative height between adjoining buildings or the slope of the ground. Therefore, an analysis of the influence of urban planning features in the seismic performance of the structures is necessary in order to obtain an adjusted approach of the damage scenarios. 


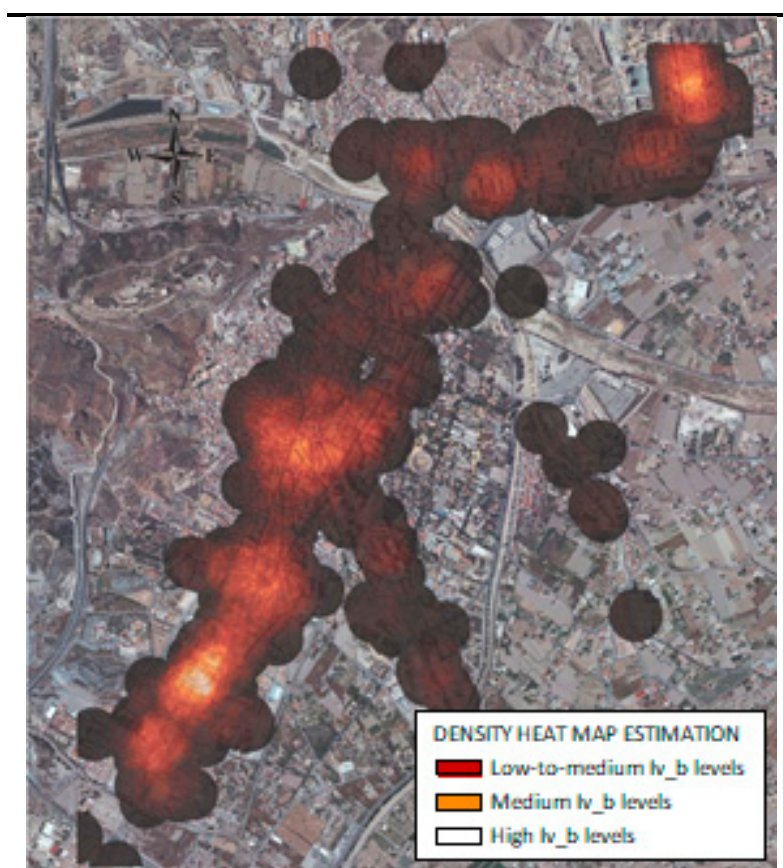

(a)

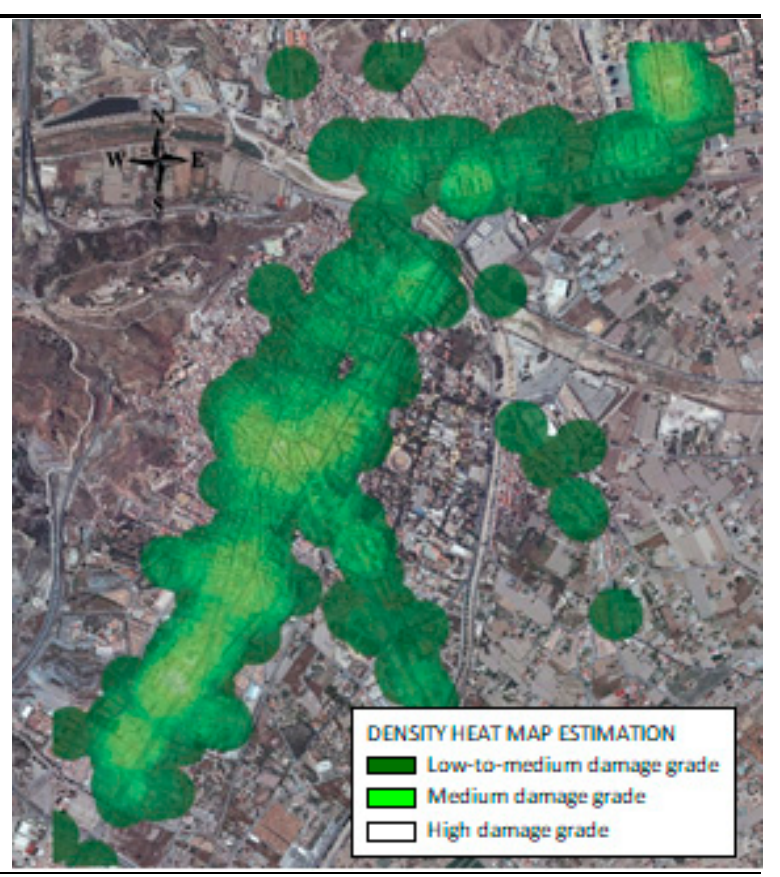

(b)

Figure 6. (a) GIS plotting of density estimation for the vulnerability indexes $I v_{b}$ of RC buildings evaluated in the city of Lorca, obtained according to the proposed model of the LM1 method. (b) GIS plotting of density estimation for the mean damage grades according to the new proposal for an $I_{E M S-98}=$ VII earthquake.

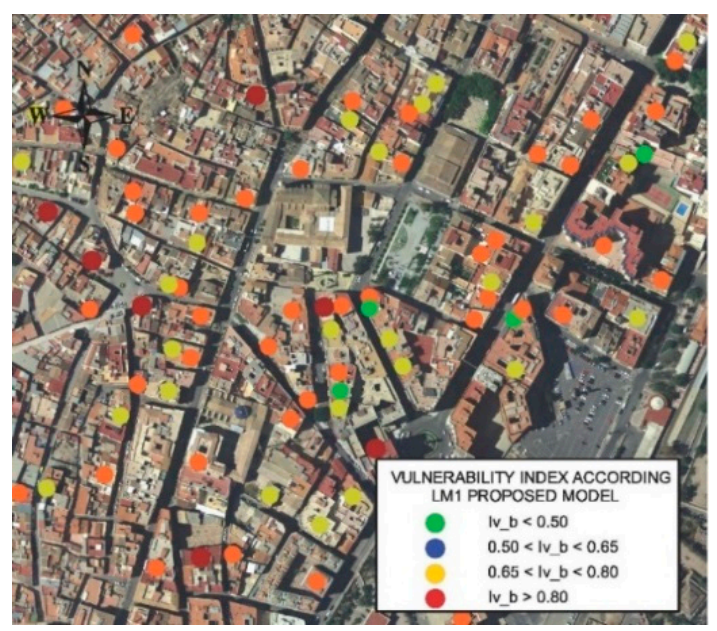

Figure 7. Detail of the urban plot in the southwestern part of the city of Lorca, including the vulnerability indexes $I v_{b}$ of analyzed RC buildings, according to the proposed model.

In this sense, the method can be applied in the decision-making process of subjects related to the emergency planning of post-earthquake situations, such as in the areas with major expected damage to buildings, the most suitable location to set up the base management camp or the assistance camps for the population, the operability of basic services and communication lines or the safest evacuation routes available in the city, in a more accurate way for a certain damage scenario.

In order to perform a more integral evaluation of the seismic risk, these results can be combined with other aspects related to the seismic hazard assessment, such as microzonation studies which determine the amplification or attenuation of local site effects of the ground motion. In this way, 
buildings with high vulnerability levels which are placed on soft soils present a considerable amplification of the local site effects and would need certain particularly accurate seismic construction requirements, in order to allow for an adequate behavior of these buildings in case of an earthquake. Moreover, the location of essential buildings such as educational centers, hospitals, or community centers in these soil types must be thoroughly analyzed due to the serious consequences of an insufficient seismic performance of these buildings.

Figure 8 shows the vulnerability indexes $I v_{b}$ of RC buildings analyzed in Lorca, obtained according to the proposed LM1 method, overlapped with the soil types identified in microzonation study of Lorca, according to EC-8 classification [41]. In this sense, the neighborhood of San Fernando in Lorca must be highlighted. The buildings in this district presented high levels of seismic vulnerability due to a soft-storey urban configuration on ground floor (see Figure 9). In addition, these buildings were located on a soft soil area with significant local site effects of ground motion amplification. Consequently, 232 homes from nine buildings had to be completely demolished after the earthquake because of the serious damage that had appeared in structural elements $[5,6,34]$.

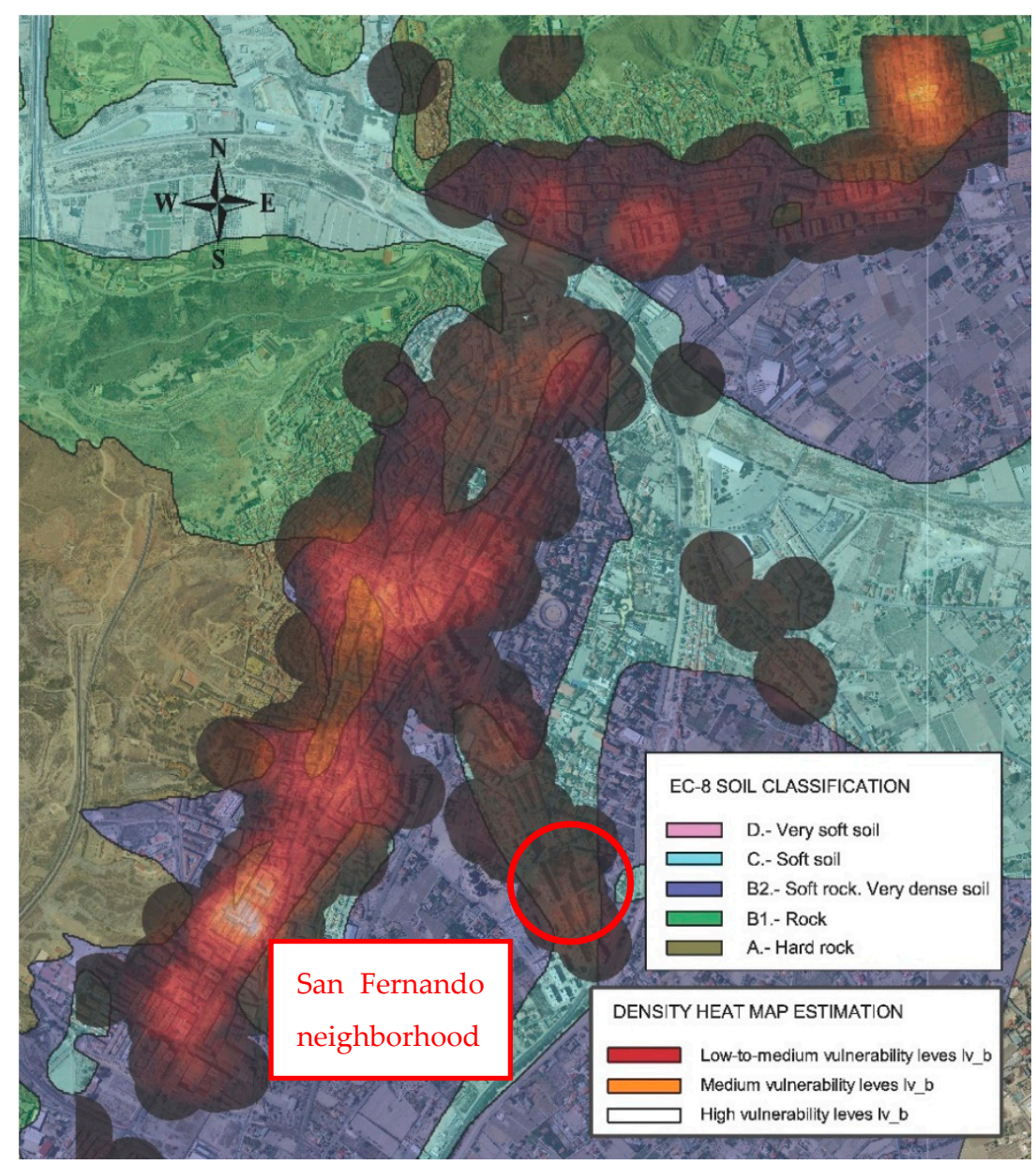

Figure 8. GIS plotting of density estimation for the vulnerability indexes $I v_{b}$ of RC buildings analyzed in Lorca, obtained according to the proposed LM1 method, overlapped with the EC-8 soil types identified in the microzonation study of Lorca. The location of the San Fernando neighborhood is highlighted. 


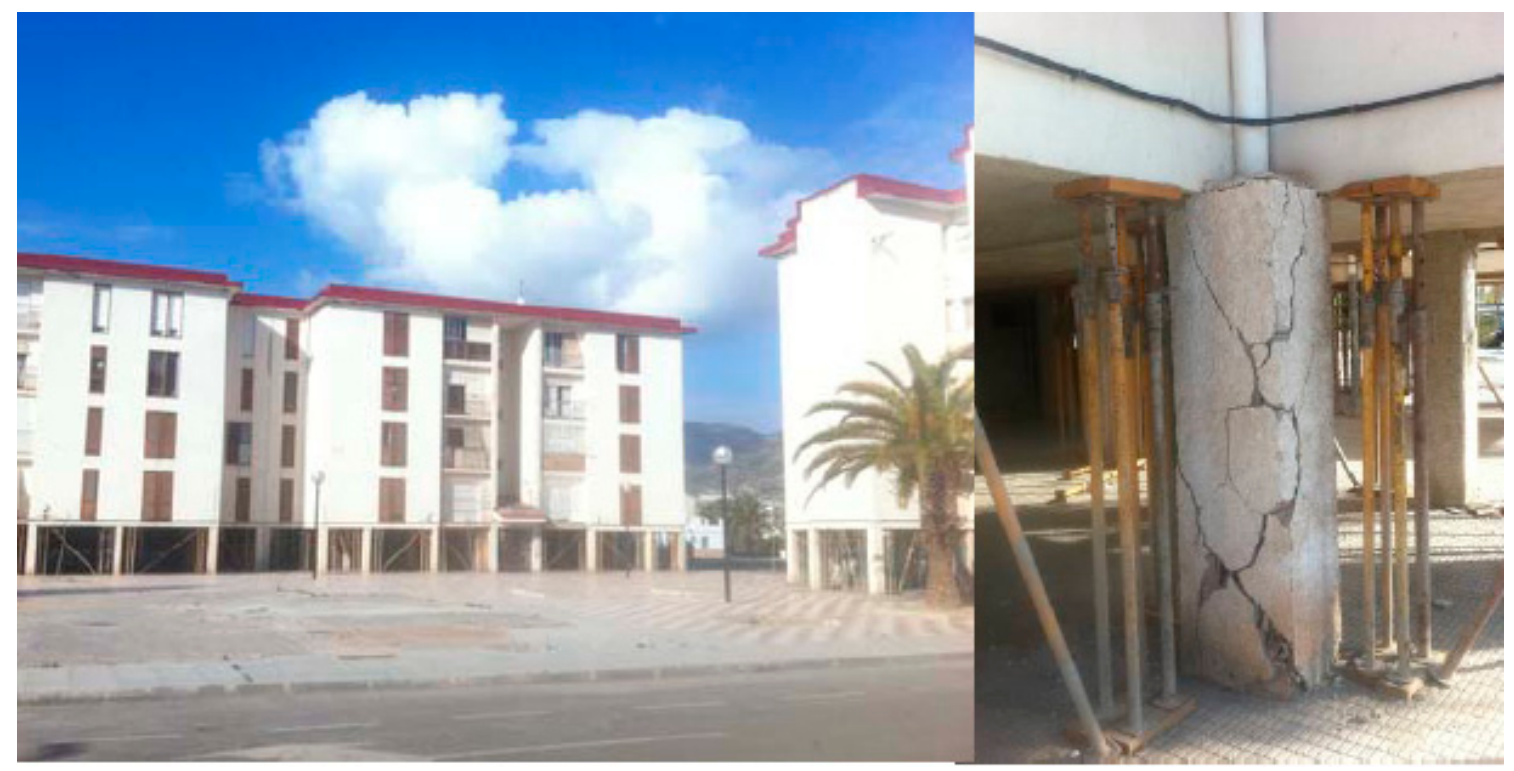

Figure 9. Overview of the San Fernando neighborhood after the 11 May 2011 earthquake [6]. Widespread damage can be observed in columns on the ground floor.

\section{Discussion}

In spite of the scientific progress made in seismic design, many territories continue to face a major level of seismic risk, mainly because of the high vulnerability of their buildings. In low-to-moderate seismic areas, the comparatively low frequency of seismic phenomena in contrast to Japan, Turkey, or Chile for example, has frequently generated a decrease in the social and institutional perception of the seismic danger.

In this sense, the conception of seismic design in urban planning is necessary in order to enhance the seismic performance of buildings in urban areas. Public administrations and institutions must develop codes regulating certain structural and urban configurations which are totally inadequate from a seismic point of view (soft storey, short column, etc.). Cases such as that of the neighborhood of San Fernando in Lorca show the lack of seismic requirements during the design and the construction of the buildings and the scant urban planning of the different seismic scenarios. In this case, the low institutional perception of the seismic threat finally led to the demolition of the district due to the impossibility of ensuring adequate future performance of the structural elements.

By using GIS tools, the most vulnerable districts of the urban area and the grade of operating conditions for the basic services and communication lines after a certain earthquake can be identified by using plot features in a detailed scale for the geospatial distribution of expected damage in buildings, providing emergency information for the management of seismic disasters and to define action protocols in real time.

Figure 10 shows a diagram for implementing the proposed model of the LM1 method applied to the analysis of the different seismic emergency situations. 


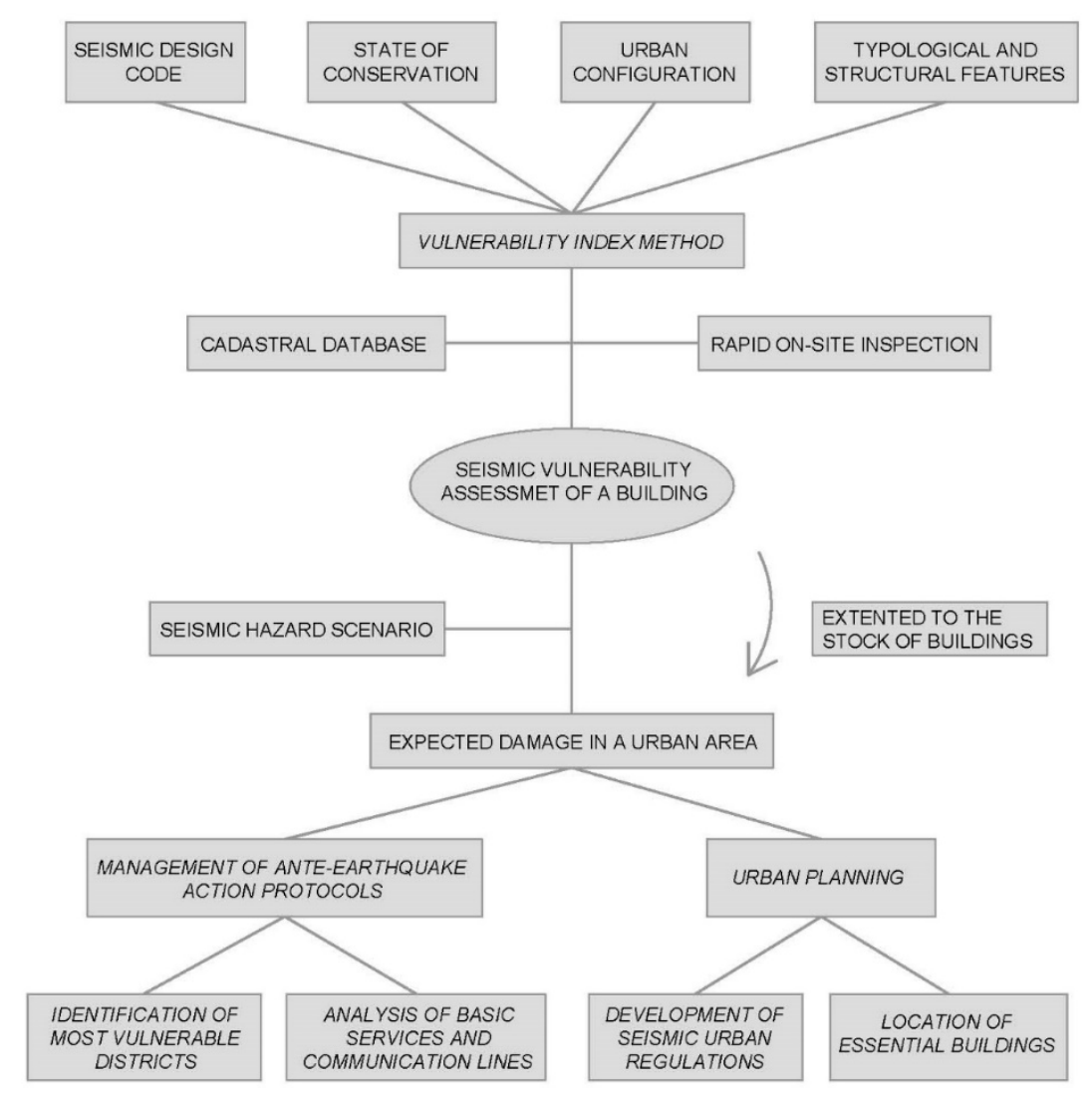

Figure 10. Diagram of the implementation of the proposed model of the LM1 method applied to the planning and management of ante-earthquake emergency scenarios. The issues developed in this contribution are italicized.

\section{Conclusions}

In this contribution, the planning and management of ante-earthquake emergency scenarios have been approached by proposing an improved method for the assessment of seismic vulnerability in urban areas, according to a review of the currently available models of LM1 methodology and an evaluation of the actual seismic performance of buildings

In comparison with the previous published works, the methodology provides an improvement in the functionality and operability of the technique with regard to the models proposed in various previous papers $[14,18,20,24,25]$, since the method can be implemented from only cadastral information and a rapid visual inspection of the evaluated zone, depending on the typological, structural, and urban parameters of the reinforced concrete buildings. Furthermore, the generalization of the proposal has been simplified in comparison with these methods by removing one parameter-the regional modifier-that requires calibration depending on the analyzed area.

Therefore, the application of the method on a large scale in urban areas has been developed in order to obtain expected damages in buildings for a certain seismic ground motion, which can be especially useful to public administrations to perform preliminary studies providing actual levels of seismic risk in a rapid and standardized way. It is necessary for these institutions to make such an effort in order to state the appropriate seismic emergency protocols.

Finally, although the verification of a seismic loss model needs to be validated in further analysis, the existence of well-documented damaging earthquakes, not so often in practice, offers an opportunity to enhance the different methodologies related to the vulnerability evaluation and seismic risk analysis of buildings in urban areas. 
Supplementary Materials: The following is available online at http:/ /www.mdpi.com/2076-3417/8/7/1208/ s1, Database summary of reported damage and seismic vulnerability assessment from the Lorca (Spain) earthquake, 2011.

Author Contributions: Conceptualization, S.G.-A., J.L.R. and A.T.; Methodology, J.L.R.; Investigation, J.L.R.; Validation, S.G.-A. and A.T.; Writing-Original Draft Preparation, S.G.-A. and J.L.R.; Writing-Review \& Editing, S.G.-A. and A.T.; Visualization, J.L.R.; Supervision, S.G.-A. and A.T.

Funding: This research received no external funding.

Conflicts of Interest: The authors declare no conflicts of interest.

\section{References}

1. Adhikari, L.B.; Gautam, U.P.; Koirala, B.P.; Bhattarai, M.; Bollinger, L. The aftershock sequence of the 2015 April 25 Gorkha-Nepal earthquake. Geophys. J. Int. 2015, 203, 2119-2124. [CrossRef]

2. Faenza, L.; Lauciani, V.; Michelini, A. The ShakeMaps of the Amatrice, M6, earthquake. Ann. Geophys. 2016, 59, 1-8. [CrossRef]

3. Ramírez-Herrera, M.T.; Corona, N.; Ruiz-Angulo, A.; Melgar, D.; Zavala-Hidalgo, J. The 8 September 2017 Tsunami Triggered by the Mw 8.2 Intraplate Earthquake, Chiapas, Mexico. Pure Appl. Geophys. 2018, 175, 25-34. [CrossRef]

4. Barbat, A.; Carreño, M.; Pujades, L.; Lantada, N.; Cardona, O.; Marulanda, M. Seismic vulnerability and risk evaluation methods for urban areas: A review with application to a pilot area. Struct. Infrastruct. Eng. 2010, 6, 17-38. [CrossRef]

5. Romao, X.; Costa, A.; Paupério, E.; Rodrigues, H.; Vicente, R.; Varum, H. Field observations and interpretation of the structural performance of constructions after the 11 May 2011 Lorca earthquake. Eng. Fail. Anal. 2013, 34, 670-692. [CrossRef]

6. García-Ayllón, S.; Tomás, A. Actions, diagnosis and territorial management of the disaster in the city of Lorca after earthquake of May 11, 2011. In Risk Analysis IX; Brebbia, C., Ed.; WIT Transactions on Information and Communication Technologies: Southampton, UK, 2013; pp. 381-392. ISBN 1845647920.

7. Applied Technology Council. Seismic Evaluation and Retrofit of Concrete Buildings, ATC-40; Scientific Research: Santa Clara, CA, USA, 1996.

8. Estimated Annualized Earthquake Losses for de United States (HAZUS-1999), FEMA-366; Federal Emergency Management Agency: Washington, DC, USA, 1999.

9. Dolsek, M.; Fajfar, P. The effect of masonry infills on the seismic response of a four-storey reinforced concrete frame: A probabilistic assessment. Eng. Struct. 2008, 30, 3186-3192. [CrossRef]

10. Tarque, N.; Candido, L.; Camata, G.; Spacone, E. Masonry infilled frame structures: State-of-the-art review of numerical modelling. Earthq. Struct. 2015, 8, 733-759. [CrossRef]

11. Bosco, M.; Ferrara, G.A.F.; Ghersi, A.; Marinoc, E.M.; Rossi, P.P. Seismic assessment of existing r.c. framed structures with in-plan irregularity by nonlinear static methods. Earthq. Struct. 2015, 8, 401-422. [CrossRef]

12. Grünthal, G. European Macroseismic Scale EMS-98; Centre Européen de Géodynamique et de Séismologie: Luxembourg, 1998.

13. Benedetti, D.; Benzoni, G.; Parisi, M. Seismic vulnerability and risk evaluation for old urban nuclei. Earthq Eng. Struct. Dyn. 1988, 16, 183-201. [CrossRef]

14. Cacace, F.; Zuccaro, G.; De Gregorio, D.; Perelli, F. Building Inventory at National scale by evaluation of seismic vulnerability classes distribution based on Census data analysis: BINC procedure. Int. Disaster Risk Reduct. 2018, 28, 384-393. [CrossRef]

15. Japan Building Disaster Prevention Association. Seismic Evaluation and Retrofits; Japan Building Disaster Prevention Association: Tokyo, Japan, 2001.

16. The Seismic Assessment of Existing Buildings; Technical Guidelines for Engineering Assessment; New Zealand Society for Earthquake Engineering: Wellington, New Zealand, 2017.

17. Federal Emergency Management Agency. Rapid Visual Screening of Buildings for Potential Seismic Hazards. A Handbook; FEMA-154; Federal Emergency Management Agency: Washington, DC, USA, 2002.

18. Milutinovic, Z.; Trendafiloski, G. WP04: Vulnerability of Current Buildings; RISK-UE Project: An Advanced Approach to Earthquake Risk Scenarios with Applications to Different European Towns; Institute of Earthquake Engineering and Engineering Seismology: Skopje, Fyrom, 2003. 
19. Chiara, M.; Lamperti, M.; Negro, P. Applicability of the Sustainable Structural Design (SSD) Method at Urban/Regional/National Level, EUR 28869 EN; Publications Office of the European Union: Luxembourg, 2017.

20. Mouroux, P.; Le Brun, B. Presentation of RISK-UE Project. Bull. Earthq. Eng. 2006, 4, 323-329. [CrossRef]

21. Lagomarsino, S.; Penna, A. Guidelines for the Implementation the II Level Vulnerability Methodology for the Vulnerability Assessment of Current Buildings; RISK-UE Project: An Advanced Approach to Earthquake Risk Scenarios with Applications to Different European Towns; European Commission: Genoa, Italy, 2003.

22. Giovinazzi, S.; Lagomarsino, S. Guidelines for the Implementation of the I Level Methodology for the Vulnerability Assessment of Current Buildings; RISK-UE Project: An Advanced Approach to Earthquake Risk Scenarios with Applications to Different European Towns; European Commission: Genoa, Italy, 2003.

23. Giovinazzi, S. The Vulnerability Assessment and the Damage scenario in Seismic Risk Analysis. Ph.D. Thesis, Technical University Carolo-Wihelmina, Braunschweig, Germany, University of Florence, Florence, Italy, 2005.

24. Lagomarsino, S.; Giovinazzi, S. Macroseismic and mechanical models for the vulnerability and damage assessment of current buildings. Bull. Earthq. Eng. 2006, 4, 415-443. [CrossRef]

25. Lantada, N.; Irizarry, J.; Barbat, A.; Goula, X.; Roca, A.; Susagna, T.; Pujades, L. Seismic hazard and risk scenarios for Barcelona, Spain, using the RISK-UE Vulnerability Index Method. Bull. Earthq. Eng. 2010, 8, 201-229. [CrossRef]

26. Applied Technology Council. Procedures for Post-Earthquake Safety Evaluation of Buildings, ATC-20; Applied Technology Council: Redwood City, CA, USA, 1989.

27. Martínez-Cuevas, S.; Benito, B.; Cervera, J.; Morillo, M.; Luna, M. Urban modifiers of seismic vulnerability aimed at Urban Zoning Regulations. Bull. Earthq. Eng. 2017, 15, 4719-4750. [CrossRef]

28. Feriche, M. Elaboration of Seismic Damage Scenarios in the City of Granada. PhD. Thesis, Technical University Granada, Granada, Spain, 2012. (In Spanish)

29. Martínez-Cuevas, S.; Gaspar-Escribano, J. Reassessment of intensity estimates from vulnerability and damage distributions: the 2011 Lorca earthquake. Bull. Earthq. Eng. 2016, 14, 2679-2703. [CrossRef]

30. Lantada, N.; Pujades, L.; Barbat, A. Vulnerability index and capacity spectrum based methods for urban seismic risk evaluation: A comparison. Nat. Hazards 2009, 51, 501-524. [CrossRef]

31. Borri, A.; Corradi, M.; Castori, G.; De Maria, A. A method for the analysis and classification of historic masonry. Bull. Earthq. Eng. 2015, 13, 2647-2665. [CrossRef]

32. Rovero, L.; Alecci, V.; Mechelli, J.; Tonietti, U.; De Stefano, M. Masonry walls with irregular texture of L'Aquila (Italy) seismic area: validation of a method for the evaluation of masonry quality. Bull. Earthq. Eng. 2016, 49, 2297-2314. [CrossRef]

33. Tomás, A.; Ródenas, J.L.; García-Ayllón, S. Proposal for new values of behaviour modifiers for seismic vulnerability evaluation of reinforced concrete buildings applied to Lorca (Spain) using damage data from the 2011 earthquake. Bull. Earthq. Eng. 2017, 15, 3943-3962. [CrossRef]

34. National Geographic Institute (IGN). Lorca Earthquake on May 11, 2011, Technical Report; National Geographic Institute (IGN): Madrid, Spain, 2011. (In Spanish)

35. De Luca, F.; Verderame, G.; Gómez-Martínez, F.; Pérez-García, A. The structural role played by masonry infills on RC building performances after the 2011 Lorca, Spain, earthquake. Bull. Earthq. Eng. 2013, 12, 1999-2026. [CrossRef]

36. Andreini, M.; De Falco, A.; Girenisi, L.; Sassu, M. Structural damage in the cities of Reggiolo and Carpi after the earthquake on May 2012 in Emilia Romagna. Bull. Earthq. Eng. 2014, 12, 2445-2480. [CrossRef]

37. Salgado-Gálvez, M.; Carreño, M.; Cardona, O.; Barbat, A. Probabilistic Seismic Hazard and Risk Assessment in Spain; International Centre for Numerical Methods in Engineering (CIMNE): Barcelona, Spain, 2015; ISBN 978-84-993307-7-3.

38. Alhama, A.; Ballesteros, J.; Blázquez, R.; Frías, A.; Gómez, J.; Guzmán, J.; Tomás, A. Rapid Evaluation of Emergency Damage: Activation and Actuation Protocols of Damage Evaluation Workgroup; General Administration of Civil Protection and Emergencies: Murcia, Spain, 2015. Available online: http:/ /www.112rm.com/dgsce/docs/Libro\%20Evaluacion\%20Rapida\%20de\%20Danos\% 20en\%20Emergencias\%20-\%20Protocolos.pdf (accessed on 13 July 2018).

39. General Administration of Civil Protection and Emergencies. Civil Protection Special Plan to the Seismic Risk in the Region of Murcia; SISMIMUR: Murcia, Spain, 2015; Available online: http:/ / www.112rm.com/dgsce/ planes /descargas/SISMIMUR\%202015.pdf (accessed on 13 July 2018). 
40. Rivas-Medina, A.; Martínez-Cuevas, S.; Quirós, L.; Gaspar-Escribano, J.; Staller, A. Models for reproducing the damage scenario of the Lorca earthquake. Bull. Earthq. Eng. 2014, 12, 2075-2096. [CrossRef]

41. Department of Public Works and Planning of the Region of Murcia. Microzonation Study in Lorca City, Technical Report; Universidad Politécnica de Cartagena: Murcia, Spain, 2014. (In Spanish) 